
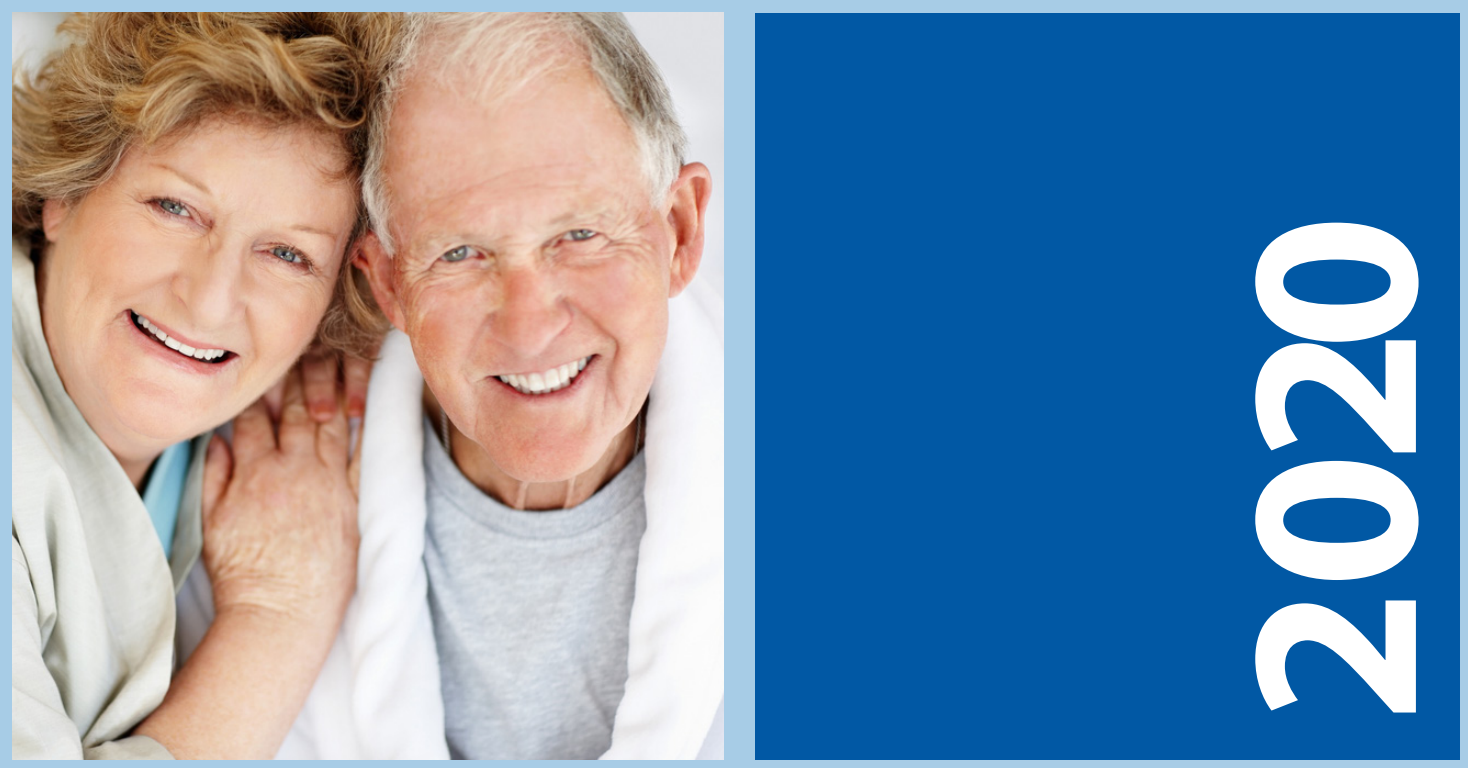

The Contributions of the Over 70 s to Irish Society: Results from Wave 5 of the Irish Longitudinal Study on Ageing

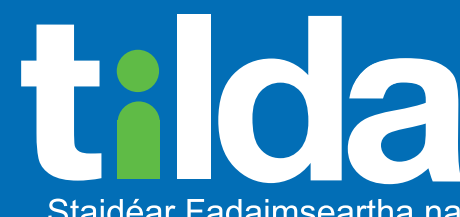

Staidéar Fadaimseartha na hÉireann um Dhul in Aois

The Irish Longitudinal Study on Ageing 


\section{The Contributions of the Over 70s to Irish Society: Results from Wave 5 of the Irish Longitudinal Study on Ageing}

Christine McGarrigle, Mark Ward, Siobhan Scarlett, Rose Anne Kenny

The Irish Longitudinal Study on Ageing

On behalf of the TILDA team

March 2020 
Copyright (C) The Irish Longitudinal Study on Ageing 2020

The Irish Longitudinal Study on Ageing

Trinity College Dublin

Dublin 2

Tel: +35318962509

Email: tilda@tcd.ie

Website: www.tilda.ie

ISBN: 978-1-907894-26-8

https://www.doi.org/10.38018/TildaRe.2020-01 


\section{Acknowledgements}

We would like to acknowledge the vision and commitment of our study funders, the Department of Health, the Health Research Board, Science Foundation Ireland, The Atlantic Philanthropies, and Irish Life plc. We would like to state that any views expressed in this report are not necessarily those of the Department of Health or of the Minister for Health. We would also like to thank the TILDA participants without whom this research would not be possible. 


\section{Contents}

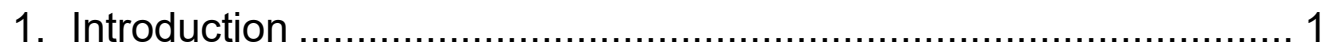

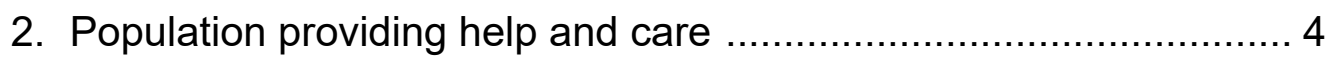

3. Population providing grandchild care ........................................ 5

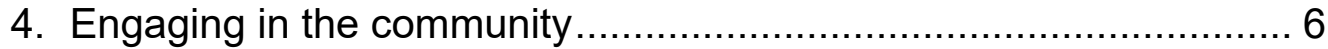

5. Social engagement and integration ....................................... 8

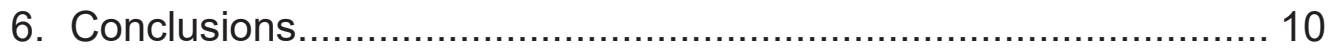

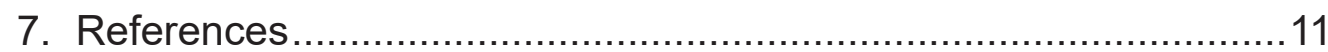




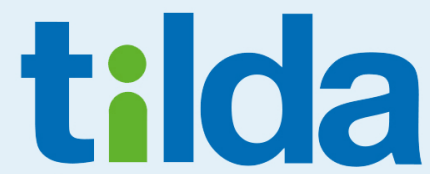

Staidéar Fadaimseartha na hÉireann um Dhul in Aois

The Irish Longitudinal

Study on Ageing

\section{ADULTS OVER 70 ARE THE FABRIC OF THEIR COMMUNITIES}

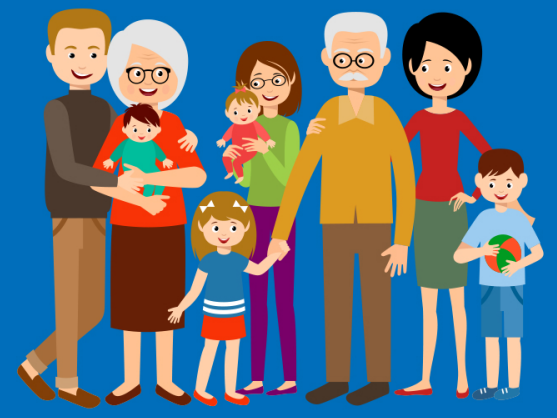

\section{CAREGIVING}

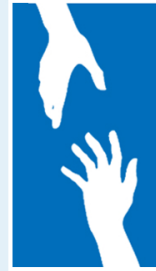

\section{2,200}

adults over 70 provided help and care for their spouses, relatives (apart from grandchildren), friends and neighbours

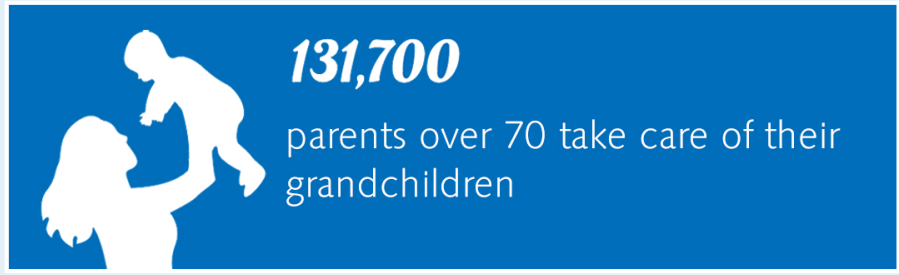

\section{FINANCIAL ASSISTANCE}

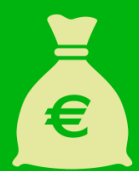

\section{8,600}

parents over 70 provide

financial assistance to their children

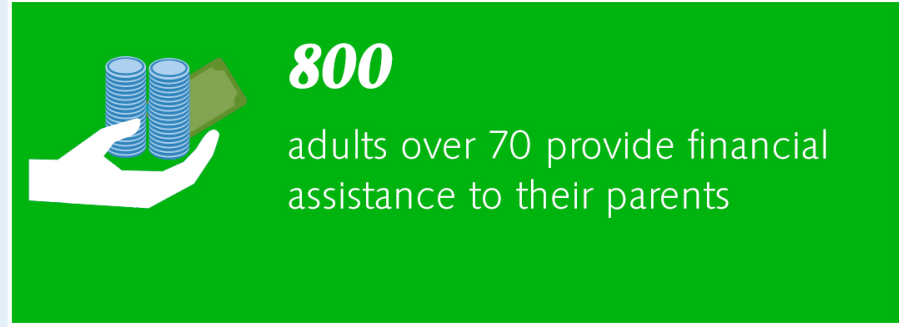

\section{ENGAGING IN THE COMMUNITY}
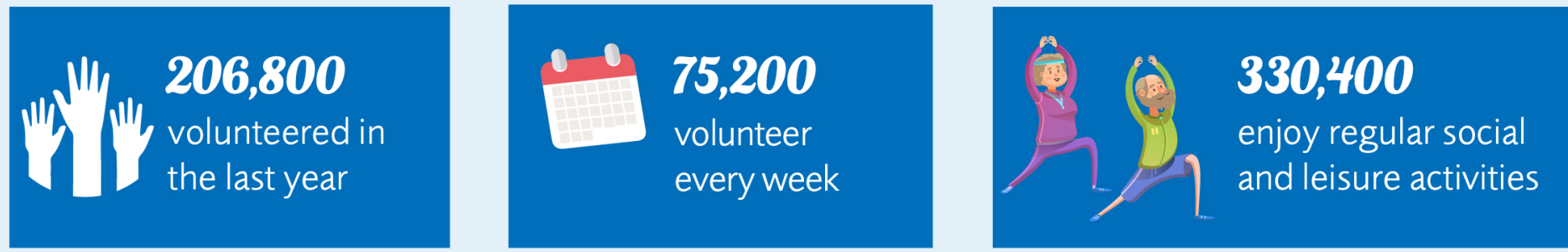

\section{SOCIAL INTEGRATION}

\section{1,200}

adults over 70 were in contact with their own parents several times each week

\section{7,600}

adults over 70 had

four or more regular contacts

For more information please visit www.tilda.ie

Supported by $\begin{aligned} & \text { An Roinn Sláinte } \\ & \text { DEPARTMENT OFHEALTH }\end{aligned}$

\section{$\underset{\substack{\text { Science } \\ \text { Sfl }}}{ }$} Ireland For what's next
The

$\underset{\text { Philanthropies }}{\text { T L A N T C Irish Life }}$ 


\section{Key Findings}

- $31 \%$ of adults (132,200 people) aged over 70 provide help and care for their spouses, relatives (not including grandchildren), neighbours and friends.

- $5 \%(21,100)$ of adults aged 70 years and over are caregivers who provide care for a median of 25 hours (range 5 to 16 hours/month). However, there are a small number of people giving very high numbers of hours of care, with an average of 64 hours per month.

- The majority $(65 \% ; 13,700)$ of those aged over 70 who report being a caregiver have become a caregiver in the last 5 years. 2 in 5 (38\%) are caring for a spouse, $55 \%$ for another relative and the remainder for friends and neighbours.

- For those who provide help with activities of daily living (ADLs), a very small number provide it to their parents $(<0.5 \% ;<100$ people $)$, while the majority are providing care for other relatives.

- Overall, $29 \%(131,700)$ of the population aged over 70 provide childcare for their grandchildren, with the median number of hours in the last month for those who provided care being 16 hours (Interquartile range 8-40).

- 23,400 adults aged 70 years and over provide more than 40 hours in the past month. This was equal to 1 in 5 of all grandparents over 70 who provided care to a grandchild.

- $206,800(47 \%)$ adults aged 70 years and over volunteered in the last year.

- $75,200(17 \%)$ adults aged 70 years and over volunteer every week.

- $330,400(60 \%)$ adults aged 70 years and over enjoy regular social and leisure activities.

- Of those adults aged 70 years and over who have living parents, 1 in $4(1,200)$ were in contact with their own parents several times each week.

- $117,600(28 \%)$ adults over 70 had four or more regular contacts. 


\section{Introduction}

\subsection{Introduction}

The older generation in Ireland have been long recognised for the vibrant and important contribution it makes to society in Ireland. Research from the Irish Longitudinal Study on Ageing (TILDA) has previously highlighted the magnitude and the importance of the contribution that the middle-aged and older population make, both to their own families, through providing help and resources to both older and younger family members (1-3), and through volunteering and active social participation in society (4).

Currently, with national resources oriented towards planning for the COVID-19 pandemic in Ireland, many discussions are taking place about the effects of the COVID-19 crisis on our older population, with progressively greater restrictions placed on social engagements introducing the possibility of social isolation for this group. We take this opportunity to once again underscore, focusing on the population aged 70 years and over, the contribution that that older persons make to society in Ireland and to the country's economic wellbeing, either directly or in indirect ways such as enabling others to take part in the workforce through their volunteering and caring.

This report uses data collected in Wave 5 of The Irish Longitudinal Study on Ageing (TILDA), a prospective study of 8,172 community-dwelling adults aged 50 years and older in Ireland. Since 2009, TILDA has collected information about the heath, wealth and social circumstances using a comprehensive Computer Assisted Personal Interview (CAPI) conducted by social interviewers who visited the participants in their own homes every 2 years (5). This included detailed questions on socio-demographics, living circumstances, income and wealth, physical, mental and behavioural health, healthcare utilisation and social participation. Participants were also asked to fill out a self-completion questionnaire (SCQ) which included more sensitive questions about relationships and experiences of growing older.

In TILDA, we ask if participants provided care for someone in the past month, and if so, for how many hours that was in the last week, and what their relationship was to those for whom they provided this care. We also ask about help they may have provided to their parents and other relatives, and whether this is help with household tasks or with 
activities of daily living (which can include help with tasks like bathing, dressing, eating and toileting). Finally, we asked about any other household help provided to neighbours and friends.

In TILDA, information about three different types of social participation - volunteering; active and social leisure activities; and organised groups $-\mathrm{s}$ collected at each wave. As part of the self-completion questionnaire (SCQ), participants are asked whether they ever volunteered during the last year and, if so, how often they did so: at least once per week; at least once per month; a few times a year or less; and never.

Information about active and social leisure activities is collected as part of the SCQ. Active and social leisure activities include going to films, plays or concerts; attending classes or lectures; playing cards, bingo, games in general; going to the pub; eating out of the house; and taking part in sporting activities or exercise.

TILDA uses a measure of the size of an individual's social network to measure social isolation. The size of social networks was measured using the Berkman-Syme Social Network Index (SNI) (6). This index is scored on a 0-4 composite scale that captures four types of social connection: (1) marital status; (2) close ties with children, relatives and friends; (3) membership of a church group; and (4) membership of voluntary organisations. A score of 0-1 identifies individuals as 'most isolated', with a score of 4 indicating 'most integrated'.

\subsection{Statistical Methods and Weighting}

In this report, all estimates are weighted to account for age, sex, educational attainment and urban/rural residence in the 2016 Census, and to reflect the probability that participants returned a completed SCQ, ensuring that these estimates are representative of the whole population aged 50 years and over in Ireland. All estimates are based on data from the most recent Wave 5 of TILDA (collected in 2018: at Wave 5, 5,206 participants took part in the study, of whom 2,402 (48\%) were aged 70 years and over), and population estimates are based on figures collected from the most recent 2016 Census data (which reported a total of 1,446,460 people over 50 living in Ireland). In all cases, population numbers have been rounded to the nearest 100 . This report focuses on the contributions that people aged 70 years and over make to society in Ireland. 


\subsection{Structure of the Report}

The report is organised as follows. The first section provides a background to the topic, describing the context for the research; it describes the questions used and the community-dwelling adults aged 70 years and over resident in Ireland who were eligible for this analysis. The second section describes the prevalence of family care. The third section describes and quantifies the numbers of older adults who are volunteers. The final section describes the prevalence of regular social and leisure activities. 


\section{Population providing help and care}

Overall, we find that $31 \%$ of adults (132,200 people) aged over 70 provide help and care for their spouses, relatives (not including grandchildren), neighbours and friends. This help takes two forms. The majority provide help with household chores for their relatives, friends and neighbours. Others provide vital care with basic activities of daily living (ADLs). These include help with bathing, dressing, eating and toileting.

We find that $5 \%(21,100)$ of those aged 70 years and over are caregivers who provide care for a median of 25 hours (range 5 to 16 hours/month) (Table 1). However, there are a small number of people giving very high numbers of hours of care, with an average of 64 hours per month.

The majority $(65 \% ; 13,700)$ of those aged over 70 who report being a caregiver have become a caregiver in the last 5 years. Two in five (38\%) are caring for a spouse, $55 \%$ for another relative and the remainder for friends and neighbours. For those who provide help with ADLs, a very small number provide it to their parents $(<0.5 \% ;<100$ people), while the majority are providing care for other relatives.

Table 1 The proportion and estimated population aged 70 years and over in Ireland providing help and care for spouses, relatives (not including grandchildren), neighbours and friends. The Irish Longitudinal Study on Ageing (TILDA)

\begin{tabular}{l|c|c|} 
& \multicolumn{3}{|c}{ Estimated Population } \\
\hline $\mathbf{N}$ & $\%$ & Population \\
\hline Providing help and care in last month & $2,282(48)$ & 426,300 \\
\hline Providing caregiving in last month & 31 & 132,200 \\
\hline Providing caregiving in last month, numbers of hours & 5 & 21,100 \\
\hline 1-20 hours & 41 & \\
\hline 20-40 hours & 18 & 6,600 \\
\hline $40+$ hours & 39 & 2,900 \\
\hline
\end{tabular}




\section{Population providing grandchild care}

Table 2 shows that, overall, $29 \%$ of the population aged 70 years and over provide childcare for their grandchildren, with the median number of hours in the last month for those who provided care being 16 hours (Interquartile range $8-40$ ). Overall, 6\% of those aged 70 years and over provided more than 40 hours in the past month. This equates to 131,700 people, with 23,400 providing more than 40 hours in the past month. This was equal to one in five of all grandparents aged 70 years and over who provided care to a grandchild.

Table 2 The proportion and estimated population aged 70 years and over in Ireland providing care for grandchildren, The Irish Longitudinal Study on Ageing (TILDA)
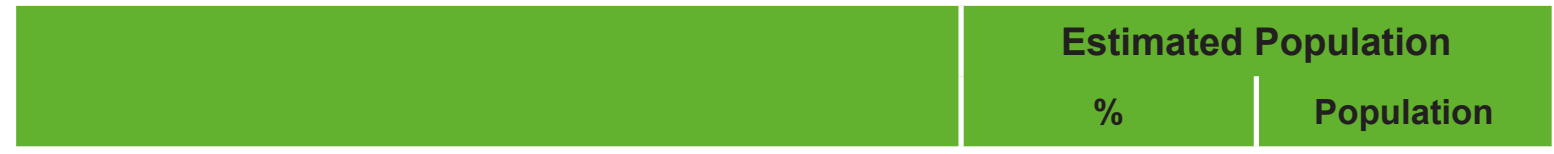

$\mathbf{N}$

$2,282(48)$

426,300

Providing care

Providing grandchild care in last month

29

131,700

Providing grandchild care in last month, numbers of hours

$1-20$ hours

62

75,000

20-40 hours

18

22,200

$40+$ hours

19

23,400 


\section{Engaging in the community}

\subsection{Volunteering}

Ireland has one of the highest rates of volunteering in the European Union. The over 70s volunteer for a wide range of organisations including: the GAA and other sports or social groups or clubs, a church-connected group, a self-help or charitable body or other community group, or a day care centre. We find that half of all those aged 70 years and over report volunteering in the last year (Table 3). This is the equivalent of 206,800 adults.

We find that more than one third of those who volunteered over the previous year did so for least one day each week. We estimate from this that 75,200 adults aged 70 years and over in Ireland are weekly volunteers.

The work of volunteers benefits hundreds of thousands of people in all age groups throughout the country. Evidence suggests volunteering also benefits the volunteers, contributing to better physical and mental wellbeing as well as overall quality of life.

Table 3 The proportion and estimated population aged 70 years and over in Ireland volunteering, The Irish Longitudinal Study on Ageing (TILDA)

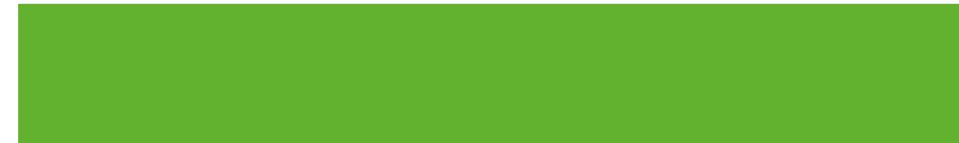

$\mathrm{N}$

Volunteered in the last year

Volunteer every week
Estimated Population

$\%$ Population

$2,282(48)$

426,300

206,800

17 75,200 


\subsection{Providing financial assistance}

Adults aged over 70 still provide financial assistance to their family members. We find $8 \%$ of those with living parents provide some financial assistance to their parents, while $35 \%$ of all adults over 70 provide financial assistance to their children (Table 4).

Table 4 The proportion and estimated population aged 70 years and over in Ireland who provided financial assistance to parents and children, The Irish Longitudinal Study on Ageing (TILDA)

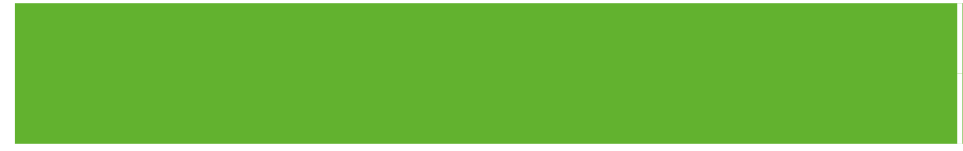

$\mathrm{N}$

Provide financial assistance to parents

Provide financial assistance to children

\section{Estimated Population}

$\%$

$2,282(48)$

Population

426,300

$<1 \quad 800$

$35 \quad 128,600$




\section{Social engagement and integration}

\subsection{Social engagement and integration}

People aged 70 years and over continue to lead active and social lives. Table 5 shows that overall, 330,400 (60\%) enjoy regular social and leisure activities. Active and social leisure activities include going to films, plays or concerts; attending classes or lectures; playing cards, bingo, games in general; going to the pub; eating out of the house; and taking part in sporting activities or exercise. These activities provide a means for people to maintain friendships, pastimes, and generally to remain engaged. The activities also support the economy. Participation in social and leisure activities has many benefits including better physical and mental health, and cognition.

Table 5 The proportion and estimated population aged 70 years and over in Ireland socially integrated in the community The Irish Longitudinal Study on Ageing (TILDA)

\begin{tabular}{l|c|c|} 
& \multicolumn{3}{|c}{ Estimated Population } \\
\hline N & $\%$ & Population \\
\hline Enjoy regular social and leisure activities & $2,282(48)$ & 426,300 \\
\hline Most isolated group (1 or fewer regular contacts) & 60 & 330,400 \\
\hline Most integrated (4 or more regular contacts) & 1 & 3,100 \\
\hline In contact with own parents several times each week & 28 & 117,600 \\
\hline
\end{tabular}

\subsection{Work}

We find that among the population aged 70 years and over $39,809800(7 \%, 13 \%$ of men and $3 \%$ of women) of the over 70 s are in full-time employment either as an employee or self-employed. Of those who are retired, 11,300 (3\%) do paid work for at least one hour per week. On average, these individuals did 19 hours of paid work per week.

\subsection{Social Integration}

A small but significant number of adults aged 70 years and over have parents themselves, with whom they are in contact several times per week. We estimate that $1,200(24 \%)$ adults over 70 with living parents are in contact with their own parents several times each week. Many of these also provide care and other help including financial assistance. 
The Contributions of the Over 70s to Irish Society: Results from Wave 5 of the Irish Longitudinal Study on Ageing

Many people over 70 maintain large social networks. Overall, one in four (117,600 (28\%)) adults over 70 has four or more regular contacts. These networks are maintained through participation in a wide range of organisations and attendance at religious services. Adults aged 70 years and over also remain close to their relatives and friends. 


\section{Conclusion}

This report demonstrates that, far from later years being a time characterised by decline and increased dependency, older adults aged 70 years and over continue to make valuable contributions to society, with many characterised by active citizenship and participation in the lives of their families and their communities. The vision for positive ageing set out in Ireland's National Positive Ageing Strategy (7), which includes a broad suite of areas targeted for action including, economic, social, cultural, community and family life, and solidarity between generations, provides a useful benchmark against which public policies and decisions, even in times of public health urgency, should be continuously assessed.

Many recent public discussions are contributing to the formation of a narrative which represents the older population of Ireland as being somewhat dependent on others, living closeted lives. Other elements of this narrative suggest that the majority are unwell and therefore require much care and confinement indoors. On the contrary, the findings of this report underscore the vibrant and important contribution that adults aged 70 years and over continue to make to society in Ireland.

With this evidence in view, and because caring for grandchildren and volunteering may not be taking place at the same scale because of recent physical distancing restrictions, support structures and assistance for families and communities who rely on the 70 plus generation to provide care will be required. This report helps to inform the extent of this current need in Ireland. 


\section{References}

1. McGarrigle, C.A., Cronin, H., \& Kenny, R.A. (2014) The impact of being the intermediate caring generation and intergenerational transfers on self-reported health of women in Ireland. International journal of public health, 59, (2) 301-308.

2. Ward, M. and McGarrigle, C. (2017) The Contribution of Older Adults to their Families and communities, in McGarrigle, C., Donoghue. O., Scarlett, S. and Kenny, R.A. Health and Wellbeing: Active Ageing for Older Adults in Ireland. Dublin: The Irish Longitudinal Study on Ageing.

3. McGarrigle, C.A., Timonen V., Layte R. (2018) Choice and Constraint in the Grandparent Role: A Mixed Methods Study, Gerontology and Geriatric Medicine, https://doi.org/10.1177/2333721417750944.

4. Ward, M. Gibney, S. Mosca, I. (2018) Volunteering and social participation, in Turner, N. Donoghue, O. and Kenny, R.A. Wellbeing and health in Ireland's over 50s 20092016. Dublin: The Irish Longitudinal Study on Ageing.

5. Donoghue OA, McGarrigle CA, Foley M, Fagan A, Meaney J, Kenny RA. (2018) Cohort Profile Update: The Irish Longitudinal Study on Ageing (TILDA). International Journal of Epidemiology, 47(5):1398-1398I.

6. Berkman LF, Syme S. Social networks, host resistance, and mortality: a nineyear follow-up study of Alameda County residents. (1979) American Journal of Epidemiology, 109(2):186-204. 